\title{
Students' experiences of using new media in higher education
}

\author{
Li Zhu \\ School of Humanities \\ College of International Business and Economics, WTU \\ Wuhan, China \\ julie0233@qq.com
}

\author{
Rui Xiong \\ Qiming School \\ Huazhong University of Science and Technology \\ Wuhan, China \\ x_ruihg@ hust.edu.cn
}

\begin{abstract}
The present study explored university students' experiences of using new media in their academic life at the University of Edinburgh. The study was conducted through semi-structured interviews with postgraduate students and their teachers at this university. It was found that new media students mainly use for learning are academic search engines, electronic resources and antiplagiarism software. These media help students learn and do research more easily, but they also pose challenges, such as causing distractions from learning. One major implication of the findings is that how students are influenced by new media depends on how they use the media in learning. This study also suggests that future research in this field should aim at developing a deeper understanding of students' reading difficulties in the digital learning environment.
\end{abstract}

Keywords—higher education; new media; university students; learning experiences; digital learning environment

\section{INTRODUCTION}

During recent decades, higher education and new media have become progressively interconnected in many of the developed countries including the UK, where higher education is even being transformed by new media [1]. Many British universities have embraced a fair high level of digitisation, as new media are widely used for academic purposes in higher education. This digital learning environment also has brought new interpretations and practices to students' learning experiences at university.

Before reviewing new media and higher education, it is important to understand what makes new media new. New media as a term emerged in the mid-1990s and it refers to advanced medium forms that are based on digital technologies and ICT (information and communication technology) [2]. Examples of new media can be generalised as computers, the Internet and derived applications of the two, contrasted to the traditional media including print journalism, radio and television [3]. The popular use of new media represents greater easiness and flexibility for information exchanges, presentation and storage, in a freer way that is across time and space. In particular, new media are able to provide users with an interface, where information in different forms, involving text, images, audio and video, are integrated, recombined and reproduced. This interface of new media is featured as highly individualised, since it is built upon users' personal needs for different purposes, such as learning, working and entertaining. Today, new media seems indispensible across the public and private sectors of everyday life, for instance, the domain of higher education.

British higher education has been profoundly influenced by new media, which have brought new interpretations and practices to students' learning experiences at university [4,5,6]. Higher education in the UK was, at one time, solely classroom-centred and campus-based [7], before being transformed by new media. Students at universities used to be provided with fixed access to learning resources, for instance, the limited storage of newspapers, journals and books in traditional libraries [8]. But today, due to the spread of new media among universities, students' academic life has become highly digitised and more liberalised than in the past. New media, such as the online space that is interconnected among personal computers, can be such a broad sharing platform, where equal opportunities are provided for individual learners to acquire huge amount of information and knowledge, and reach different sorts of learning resources as much as possible. In fact, not only do students prefer to use new media to meet a variety of learning needs of their own, but universities are also supporting the wide use of new media in a wise way for learning-related purposes [9] [10].

The popularisation of new media products designed for learning, such as academic web search engines, electronic learning resources and related software, has led to both opportunities and challenges for students' academic life at university. With collections of academic resources shared online, there has been some argument about the value of using these for study and research. There is some voice arguing that acknowledging e-books and e-journals in essays is less worthy than acknowledging print ones [11]. However, at least in the British context, research has shown that in reality the two forms of scholarly literature are evenly valuable as long as they are formally published and peer-reviewed, no matter online or on paper [12]. Moreover, the online sharing of electronic resources can help re-invent the learning process, such as online learning and self-study before and after class [13]. 
Students can enjoy diversified experiences of learning through the way they choose for themselves and at a time they prefer to learn. Therefore, not only is a broader awareness of self-directed learning achieved across the universities, but students are also likely to engage more in independent or collaborative learning activities.

As a key promoter of the spread of electronic resources, digital library services have developed rapidly in the UK. Modern British universities have built their own virtual libraries and literature search engines, with subscription to many large academic databases online [14]. A great number of public libraries also participated in building the virtual ones, with their own resources digitised and shared for the sake of public benefits [15]. Services like these greatly facilitate users' easier access to the expanding amount of learning resources, linking academic collections available in a specific university library to a wide range of other libraries and online databases. It is fairly convenient for students to search, read and download papers and books, or share links with people, via the university library portal.

Studies on media in education also pay attention to the wider process of how students are affected by their own use of media [16]. Today's students tend to be native to new media as they grow up in a digital environment. They can be experts of digital products, and are often perceived as handling information faster than older generations. To students, as mentioned, literature searching and accessing now become much easier, but this does not definitely lead to better academic performance. It is an emerging issue of academic misconduct in higher education that students' inappropriate use of the Internet in learning may cause Internet-based plagiarism [17]. It is just the convenience of new media that makes some students too lazy to transfer other people's ideas to their own, but copy them either directly or indirectly. In response, anti-plagiarism software, such as Turnitin, has been introduced to more than 90 per cent of the universities in the UK [18]. Literately and practically, the software helps students avoid plagiarism, and therefore, academic honesty can be improved.

Besides that, students may have developed some new style of learning, whilst exposed to the digital learning environment constantly. Since new media, such as the Internet, provide new forms of inquiry, discussion, and knowledge acquisition, learning has become increasingly self-directed, collaborative and problem-based [19]. Moreover, with new media, students are allowed to personalise their learning, by organising learning activities at any place, and based on different learning needs. But meanwhile, the media can also have negative effect. For instance, Facebook is proved to be distractive in learning, with friends' messages or something more attractive popping up instantly [20]. In cases like this, strong self-discipline becomes rather essential to students, who may be aware of distraction, but still using the media for non-academic purposes during the learning process.

To conclude, today's students rely on new media for learning more than ever, and the researcher is interested in how university students interact with, and become influenced by new media in their academic life. However, to date, few studies have investigated this issue. It indicates a gap in the research on new media and higher education and, consequently, the researcher aimed to narrow this gap with the current research project located in the UK.

\section{RESEARCH AIM AND RESEARCH DESIGN}

The main aim of this study is to explore university students' experiences of using new media in their academic life in the case of the University of Edinburgh. The researcher was a postgraduate student in the Moray House School of Education at this university. According to the researcher's knowledge, the majority of postgraduate students hold the belief that new media have become an essential tool for learning, as students often depend on computers and the Internet during their learning process. Thus, the present study is located in the context of the University of Edinburgh and the research questions are formulated as follows:

The main question: What are university students' experiences of using new media in their academic life?

Sub-questions: 1. What kinds of new media do students often use, and how do they use the media in their academic life? 2. How do new media impact on students' academic life? 3. In what ways can students' experiences of new media be improved?

This study was conducted through semi-structured interviews that cover these questions with four postgraduate students and two of their teachers at the University of Edinburgh. The choices of individual participants were based on purposive sampling, which means the participants were targeted on the basis that they might have some knowledge of new media and higher education, and were perceived as using new media quite often in their own academic life. Qualitative data was gathered from the face-to-face interviews that took place at the university in June, 2016. The collected data was then analysed with thematic coding.

\section{RESEARCH FINDINGS AND DISCUSSION}

The findings of the interviews will be reported from an integrated perspective of postgraduate students and their teachers, and will be discussed according to the main themes emerging from the collected data.

\section{A. Theme 1: the types of new media used by postgraduate students and students' experiences of working with them}

All of the participants reported that the types of new media students use most often are academic search engines, electronic resources and anti-plagiarism software.

As for literature search engines, the participants all agree that Google Scholar and DiscoverEd (the digital library service provided by the University of Edinburgh), either, or both, are widely used by university students to access scholarly literat ure. 
According to the participants, although DiscoverEd seems to be more academic and reliable, Google Scholar tends to be more professional as a search engine, and more user-friendly. Students may use Google Scholar more often because it highlights the simplicity in usage, and tends to have richer results with higher relevancy than DiscoverEd. It is also reported that students often turn to DiscoverEd when resources are not freely accessible in Google Scholar. DiscoverEd allows students to download full text without any charge, so it becomes a better choice for accessing literature. Overall, students prefer to use Google Scholar more than DiscoverEd, and they both require students to develop searching strategies to make the best use of them.

Considering electronic resources, such as chapters of books and journal articles, all participants, both students and teachers, agree it is progress that the digitisation of academic resources makes learning easier than before. Students may download the chapters and articles within seconds, instead of struggling to borrow or pay for them. Some students think it efficient to read literature on computers, whereas others confess that their concentration on reading decreases to some extent.

With regard to anti-plagiarism software required to use in the University of Edinburgh, Turnitin, both students and teachers agree that it plays an essential and helpful role in postgraduate study, although it should be more intelligent. Students interviewed reported that Turnitin is very competent in plagiarism detection as it always alarms and helps students to identify whether they use sources properly and develop their own understandings. It is convenient to read and modify the similarities accordingly due to colour-coded originality reports generated with matching text. However, students also complain about Turnitin's mechanical judgment of potential plagiarism, when they do not plagiarise and get a high similarity rate, even including references.

\section{B. Theme 2: the impact of new media on postgraduate study}

New media can both benefit and pose challenges to postgraduate study. From students' perspective, new media can help them concentrate on learning, educational resources and all files of tasks can be well-organised and stored in personal computers or online. Specially, new media make different forms of information (text, images, audio and video) integrated on one interface, which is designed, or awaits users to design, for their personal needs. Users are allowed to search, access, create and store any form of information on this platform of new media. Since diversified learning resources needed are now centralised, recombined and reproduced, learning is likely to become more integrated, efficient and innovative.

New media can also benefit learning by providing students with learning opportunities that are more flexible, regardless of time and place. This means that students now have a variety of choices concerning how to learn. They can study on or outside the campus, work traditionally with books and pens or with computers and other new media applications, handle learning resources and conduct learning activities in reality with friends or in the virtual learning environment. Thus, students' learning experiences become increasingly individualised on new media, where students can enjoy more flexibility, efficiency and independence in learning.

From the teachers' perspective, new media integrates learning approaches and make students better interacted with teachers. Students can easily find resources shared by their teachers on Learn (the virtual learning environment of the University of Edinburgh), such as course information, weekly readings and links of extended reading. Furthermore, Learn makes discussion workshops, assignment uploading and marking all available online. New media, therefore, make learning more integrated and easier, by which students get used to individualised and collaborative learning styles in a digital environment.

Apart from the benefits, new media also bring challenges to learning. In a digital learning environment, students may get distracted easily in both classroom learning and independent study, as their attention is often caught by advertisements and other irrelevant entertaining information shown on the media, or messages popping up automatically from Facebook or somewhere. But media like Facebook are actually good tools for peer discussion and teacher-student interaction, only if they are used properly by students who have strong self-discipline.

Besides, new media is considered to have a negative impact on students' depth of reading. Younger generations that grow up in a digital environment tend to find it difficult to maintain an extended amount of reading, and their understandings of reading sometimes are to some extent superficial. The reason may be a lack of concentration, or they are just not used to settling down to read and think critically. The researcher suggests that future research in this field should aim at exploring reading difficulties of this sort and work out their solutions.

\section{Theme 3: the ways that students' experiences of new media in postgraduate study can be improved}

Both students and teacher think that students should develop stronger self-discipline and learn to organise learning with wise time management during their postgraduate study. Self-discipline is a key factor in students' academic life at university and can affect learning outcomes directly. University students as adults should be responsible for their own behaviour in learning rather than rely on teachers. It is important that students demonstrate enough self-discipline and organise learning by balancing learning tasks and the focus on new media, that is, wise time management, especially in self-study. Overall, how students are influenced by new media depend on how they use the media for learning. The media can be an effective learning tool if they are used properly for academic purposes. 


\section{CONCLUSION}

The present study has explored the overarching research question related to university students' experiences of using new media in their academic life. Qualitative data was gathered though semi-structured interviews with four postgraduate students and two of their teachers at the University of Edinburgh. The findings show that students in this university mainly use academic search engines, electronic sources and anti-plagiarism software for learning. Generally, these new media can help students learn easier and achieve better academic performance. But meanwhile, they also pose challenges to learning, such as causing distractions. One major implication of the findings is that whether students use new media properly for learning determines the impact of new media on their learning outcomes. The study also suggests that future research in this field should aim to develop a deeper understanding of students' difficulties in the digital learning environment, such as reading problems.

\section{ACKNOWLEDGEMENT}

I would like to take this opportunity to offer my special thanks to the people who have contributed to my research project.

Firstly, I would like to express my sincere gratitude to my supervisor Ms. Iryna Kushnir, for her continuous guidance, support and encouragement throughout the dissertation process.

My appreciation also goes to Prof. Rui Xiong for offering suggestions for my paper, and sharing this opportunity to attend CETCU 2017 with me.

Finally, I want to thank the teachers and students at the University of Edinburgh, who helped me in many ways and spared their precious time to participate in my research.

\section{REFERENCES}

[1] D. Lupton, Digital Sociology, London: Routledge, 2014.

[2] S. Cunningham, New Media and Borderless Education: A Review of the Convergence between Global Media Networks and Higher Education Provision, Canberra: Department of Employment, Education, Training and Youth Affairs, 1997.

[3] K.B. Jensen, Introduction: the state of convergence in media and communication research, in A Handbook of Media and Communication Research: Qualitative and Quantitative Methodologies, K.B. Jensen, Ed. London: Routledge, 2013, pp. 1-14.

[4] J. Hutton, "Academic libraries as digital gateways: linking students to the burgeoning wealth of open online collections", Journal of Library Administration, vol. 48, pp. 495-507, 2008.

[5] D. Nicholas et al., "UK scholarly e-book usage: a landmark survey", Aslib Proceedings, vol. 60, pp. 311-334, 2008.

[6] M. Weller, The Digital Scholar: How Technology Is Transforming Scholarly Practice, London: Bloomsbury Academic, 2011.

[7] R.N. Katz and J.A. Rudy, Information Technology in Higher Education: Assessing Its Impact and Planning for the Future: New Directions for Institutional Research, San Francisco: Jossey-Bass, 1999.

[8] N.H. Dewald, "Transporting good library instruction practices into the web environment: an analysis of online tutorials", The Journal of Academic Librarianship, vol. 25, pp. 26-31, 1999.

[9] M. Moran, J. Seaman and H. Tinti-Kane, "Teaching, learning, and sharing: how today's higher education faculty use social media", Wellesley: Babson Survey Research Group, 2011.

[10] R. Kitchin, D. Linehan, C. O'Callaghan and P. Lawton, “Public geographies through social media”, Dialogues in Human Geography, vol. 3, pp. 56-72, 2013.

[11] M. Weller, The Digital Scholar: How Technology Is Transforming Scholarly Practice, London: Bloomsbury Academic, 2011.

[12] C. Tenopir and D.W. King, "Reading behaviour and electronic journals", Learned Publishing. vol.15, pp. 259-265, 2002.

[13] W.H. Dutton and B.D. Loader, "New media and institutions of higher education and learning", in Digital Academe: New Media in Higher Education and Learning, W.H. Dutton and B.D. Loader, Eds. London: Routledge, 2005, pp. 1-32.

[14] D. Nicholas et al., "UK scholarly e-book usage: a landmark survey”, Aslib Proceedings, vol 60, pp. 311-334, 2008.

[15] J. Hutton, "Academic libraries as digital gateways: linking students to the burgeoning wealth of open online collections", Journal of Library Administration, vol. 48, pp. 495-507, 2008.

[16] M. Lister, New Media: a Critical Introduction, Abingdon: Taylor \& Francis, 2009.

[17] W. Sutherland-Smith and R. Carr, "Turnitin.com: teachers' perspectives of anti-plagiarism software in raising issues of educational integrity", Journal of University Teaching \& Learning Practice, vol 2, pp. 94-101, 2005.

[18] A. Ledwith and A. Risquez, "Using anti-plagiarism software to promote academic honesty in the context of peer reviewed assignments", Studies in Higher Education. vol 33, pp. 371-384, 2008.

[19] H. Beetham and R. Sharpe, Rethinking Pedagogy for a Digital Age: Designing For $21^{\text {st }}$ Century Learning, London: Routledge, 2013.

[20] S. Dietz and C. Henrich, "Texting as a distraction to learning in college students", Computers in Human behavior, vol 36, pp. 163-167, 2014. 